\title{
Biomassa e nutrição mineral de forrageiras cultivadas em solos do semiárido adubados com esterco
}

\author{
Eduardo R. Araújo무, Tácio 0. da Silva², Rômulo S. C. Menezes ${ }^{3}$, \\ Vânia da S. Fraga ${ }^{1} \&$ Everardo V. de S. B. Sampaio ${ }^{3}$
}

\begin{abstract}
RESU MO
A produção de biomassa e as absorções de $\mathrm{N}, \mathrm{P}$ e $\mathrm{K}$ de quatro espécies forrageiras foram comparadas em três solos representativos da regiấo semi-árida da Paraíba, cultivadas sem e com adubação orgânica. As espécies foram jureminha (D esmanthus virgatus), orelha-de-onça (M acroptilium martii), feijão-derolinha (Macroptilium lathyroides) e capim buffel (Cenchrus ciliaris); os solos foram Neossolo Flúvico, Neossolo Regolítico e Planossolo Háplico e a adubação foi realizada com esterco bovino (20 M g ha-1) comparado com a testemunha. A adubação com esterco promoveu grandes incrementos na produção de biomassa e nas acumulações dos nutrientes, em todas as plantas e solos. 0 esterco parece ter suprido $P$ às plantas em quantidades suficientes mas não de $\mathrm{N}$ e $\mathrm{K}$, confirmando que é uma boa fonte do primeiro elemento. 0 feijão de rolinha e a orelha de onça tiveram as maiores capacidades de acumulação de biomassa, principalmente em resposta à adubação. 0 capim buffel atinge maiores teores e conteúdos de $\mathrm{K}$ na matéria seca que as leguminosas. $\mathrm{N}$ ão houve correspondência entre a análise dos solos e sua capacidade de suprimento de nutrientes.
\end{abstract}

Palavras-chave: nitrogênio, fósforo, potássio, leguminosas, adubação orgânica

\section{Biomass and mineral nutrition of forage grown in the semi-arid soils fertilized with manure}

\begin{abstract}
Biomass production and $\mathrm{N}, \mathrm{P}$ and $\mathrm{K}$ uptake by four forage species were compared in three soils from the semi-arid region of Paraíba, with or without organic manure. The species were three legumes (D esmanthus virgatus, Macroptilium martii and Macroptilium lathyroides) and one grass (Cenchrus ciliaris); the soils, a Fluvic $\mathrm{Neosol}$, a Regolithic $\mathrm{Neosol}$ and $\mathrm{Haplic}$ Planosol; and cattle manure was applied at a dose equivalent to $20 \mathrm{Mg} \mathrm{ha}^{-1}$. Manure application resulted in large increases in biomass production and nutrient uptake, in all species and soils. Apparently, the manure supplied enough P but not enough $\mathrm{N}$ and $\mathrm{K}$ to the plants, confirming that it is a good source of the first nutrient. Macroptilium martii and Macroptilium lathyroides seem to be the highest biomass producers, mainly in response to fertilization. Cenchrus ciliaris had higher $\mathrm{K}$ concentrations and contents than the legumes, indicating a larger $\mathrm{K}$ absorption capacity. There was no correspondence betw een soil analysis and nutrient supplying capacity.
\end{abstract}

Key words: nitrogen, phosphorus, potassium, legumes, organic manure 


\section{INTRODUÇÃO}

Na região semiárida nordestina o desmatamento e o aumento da exploração agrícola vêm reduzindo significativamente as coberturas florestais, provocando degradação do bioma Caatinga e diminuindo a fertilidade do solo. Esta redução dos teores de nutrientes do solo é causada pela erosão e pela exportação dos nutrientes dos produtos agrícolas e da pecuária (Menezes \& Sampaio, 2000; Fraga \& Salcedo, 2004). Neste contexto se tem buscado alternativas que minimizem o processo de degradação e melhorem a fertilidade dos solos. Assim, o uso de forrageiras nativas como adubação verde, combinado ou não com a aplicação de esterco, é uma dessas alternativas de melhoria (Silva et al., 2007).

A utilização de esterco é outra solução amplamente adotada para o suprimento de nutrientes, tais como N, P e K nos solos da região semiárida (Menezes \& Silva, 2008); no entanto, devido à sua reduzida disponibilidade nas propriedades, em geral os agricultores necessitam comprá-los de regiões circunvizinhas, o que eleva os custos de produção. Alguns ainda vendem parte do esterco produzido na propriedade, como renda extra (Menezes \& Sampaio, 2002; Silva et al., 2007; Silva \& Menezes, 2007; Menezes \& Silva, 2008; Galvão et al., 2008).

A adubação verde pode reduzir as necessidades de esterco, sobretudo quando a carência maior é de $\mathrm{N}$ e a forrageira usada é uma leguminosa capaz de fixação simbiótica do $\mathrm{N}_{2}$ atmosférico (Franco \& Neves, 1992; Moreira \& Siqueira, 2006); no entanto, há pouca informação sobre a capacidade de fixação das espécies de leguminosas nativas do semiárido (Martins et al., 2003, Teixeira et al., 2006; Souza et al., 2007, Sampaio \& Freitas, 2008), ao contrário de outras regiões (Krolow et al., 2004, Patreze \& Cordeiro, 2005, Xavier et al., 2007; Ambrosano et al., 2009); com isto, vem a urgência de se ampliar esses estudos para espécies forrageiras, leguminosas e não leguminosas, buscando-se aquelas que se destacam quanto à capacidade de suprimento de nitrogênio e ciclagem de nutrientes nos solos.

Objetivou-se, ante este contexto, avaliar o potencial de espécies forrageiras quanto à produção de biomassa e à absorção de nutrientes (N, P e K), com e sem aplicação de esterco, quando cultivadas em solos representativos da região semiárida.

\section{Material e mÉtodos}

O experimento foi conduzido em vasos, em casa de vegetação, no Departamento de Solos e Engenharia Rural do Centro de Ciências Agrárias (CCA), da Universidade Federal da Paraíba (UFPB), no município de Areia, a $6^{\circ} 58^{\circ}$ de Latitude Sul e $35^{\circ} 41^{\prime}$ de Longitude Oeste e $575 \mathrm{~m}$ de altitude. Pela classificação de Köppen, o clima é do tipo AS', que se caracteriza por ser quente e úmido e temperatura média anual oscilando entre 23 e $24^{\circ} \mathrm{C}$, com variações mensais mínimas.

Utilizou-se o delineamento experimental inteiramente casualizado, de acordo com o arranjo fatorial $4 \times 3 \times 2$, correspondendo a quatro espécies forrageiras, três tipos de solo e dois níveis de adubação, com quatro repetições. As quatro espécies forrageiras foram: jureminha, Desmanthus virgatus; orelha-de-onça, Macroptilium martii (Benth.) Marechal \& Baudet; feijão-de-rolinha, Macroptilium lathyroides (L.) Urban e capim buffel, Cenchrus ciliaris L. Os três solos utilizados foram: Neossolo Flúvico, Neossolo Regolítico e Planossolo Háplico. Os dois níveis de adubação se constituíram de uma dose de esterco bovino ( $55 \mathrm{~g}$ de esterco por vaso, correspondendo a $20 \mathrm{Mg} \mathrm{ha}^{-1}$ ) e a testemunha, sem adubação.

Escolheram-se o Neossolo Flúvico na região do agreste da Paraíba, no município de Esperança, o Neossolo Regolítico no Brejo Paraibano e o Planossolo Háplico na microrregião do Curimataú Paraibano, no município de Remígio. Amostras desses solos foram coletadas na camada de 0 a $0,2 \mathrm{~m}$ de profundidade, secadas ao ar e passadas em peneira de $2 \mathrm{~mm}$, constituindo a terra fina secada ao ar (TFSA). Subamostras foram retiradas para a caracterização química e física, conforme a Tabela 1 .

Tabela 1. Atributos químicose físicos dos solos utilizados no ensaio, antes da aplicação dos tratamentos

\begin{tabular}{|c|c|c|c|}
\hline Atributos & $\begin{array}{c}\text { Neossolo } \\
\text { Flúvico }\end{array}$ & $\begin{array}{l}\text { Neossolo } \\
\text { Regolítico }\end{array}$ & $\begin{array}{l}\text { Planossolo } \\
\text { Háplico }\end{array}$ \\
\hline pH em água $(1: 2,5)$ & 6,40 & 6,50 & 7,40 \\
\hline P-Mehlich-1 (mg dm $\left.{ }^{-3}\right)$ & 8,10 & 3,70 & 1,00 \\
\hline $\mathrm{K}^{+}-$Mehlich-1 $\left(\mathrm{mg} \mathrm{dm}^{-3}\right)$ & 33,80 & 140,40 & 23,40 \\
\hline $\mathrm{Ca}^{2+}-\mathrm{KCl} 1 \mathrm{~mol} \mathrm{~L}^{-1}\left(\mathrm{cmol}_{\mathrm{c}} \mathrm{dm}^{-3}\right)$ & 2,85 & 1,84 & 4,40 \\
\hline $\mathrm{Mg}^{2+}-\mathrm{KCl} 1 \mathrm{~mol} \mathrm{~L}^{-1}\left(\mathrm{cmol}_{\mathrm{c}} \mathrm{dm}^{-3}\right)$ & 0,65 & 1,00 & 3,10 \\
\hline $\mathrm{Al}^{3+}-\mathrm{KCl} 1 \mathrm{~mol} \mathrm{~L}^{-1}\left(\mathrm{cmol}_{\mathrm{c}} \mathrm{dm}^{-3}\right)$ & 0,0 & 0,04 & 0,0 \\
\hline $\mathrm{SB}\left(\mathrm{cmol}_{\mathrm{c}} \mathrm{dm}^{-3}\right)$ & 3,58 & 3,20 & 7,56 \\
\hline $\mathrm{t}\left(\mathrm{cmol}_{\mathrm{c}} \mathrm{dm}^{-3}\right)$ & 3,58 & 3,24 & 7,56 \\
\hline$m(\%)$ & 0,0 & 1,23 & 0,0 \\
\hline Carbono Orgânico $\left(\mathrm{g} \mathrm{kg}^{-1}\right)^{1}$ & 13,70 & 5,67 & 13,70 \\
\hline Areia $\left(\mathrm{g} \mathrm{kg}^{-1}\right)^{2}$ & 657,00 & 805,00 & 686,00 \\
\hline Silte $\left(\mathrm{g} \mathrm{kg}^{-1}\right)^{2}$ & 114,00 & 110,00 & 209,00 \\
\hline Argila $\left(\mathrm{g} \mathrm{kg}^{-1}\right)^{2}$ & 229,00 & 85,00 & 105,00 \\
\hline
\end{tabular}

${ }^{1}$ Snyder \& Trofymow (1984)

2EMBRAPA (1997)

Porções de $7 \mathrm{~kg}$ de cada solo foram colocadas em vasos de polietileno e neles aplicados os tratamentos. O esterco foi misturado a uma profundidade de $15 \mathrm{~cm}$ e os vasos mantidos a $50 \%$ da capacidade de campo, irrigados diariamente com água destilada, durante 15 dias, para início da mineralização dos nutrientes. Sementes das leguminosas e do capim buffel, coletadas no município de Taperoá, PB, foram semeadas em bandejas plásticas com areia lavada; após a germinação as plântulas foram transplantadas para os vasos e depois desbastadas, deixando-se apenas uma plântula por vaso. Com o desenvolvimento das plantas tornou-se imprescindível a utilização de tutores de madeira para facilitar a condução e manutenção do experimento. Fez-se a colheita das plantas em períodos diferentes, em que a parte aérea de cada uma delas foi sendo cortada e colhida quando cada uma terminava seu ciclo fenológico até que, aos 130 dias depois do transplante, se cortaram todas as plantas restantes.

As partes aéreas foram colocadas em estufa de circulação forçada a $65^{\circ} \mathrm{C}$ até atingir o peso constante. Após a pesagem se retiraram amostras vegetais da biomassa da parte aérea (folhas e caules), que foram moídas em moinho tipo Wiley e digeridas com uma mistura de ácido sulfúrico e peróxido de 
hidrogênio para obtenção do extrato usado para a determinação dos teores de N, P e K, de acordo com a metodologia descrita por Malavolta et al. (1997).

As variáveis analisadas foram massa seca da parte aérea, teores e acúmulos de N, P e K na parte aérea. Os dados foram submetidos à análise de variância e as médias comparadas pelo teste de Tukey a 5\% de significância, utilizando-se o programa estatístico Sisvar (Ferreira, 2003).

\section{Resultados E DisCUSSÃo}

\section{Biomassa}

No geral, a aplicação do esterco nos solos promoveu aumentos na biomassa seca da parte aérea das forrageiras cultivadas (Tabela 2); esses aumentos foram maiores no Neossolo Flúvico, correspondendo a incrementos de três até dez vezes na biomassa das plantas. No Neossolo Regolítico os incrementos foram de duas a quatro vezes enquanto no Planossolo Háplico foram, no máximo, duas vezes e, no caso do buffel, sequer houve aumento na biomassa em relação ao tratamento sem esterco o que, porém, não significa inferioridade do Planossolo mas, ao contrário, as maiores produções foram obtidas neste solo visto que as respostas foram função das produções no tratamento testemunha; enquanto no Neossolo Flúvico, neste tratamento, variaram de 2,0 a $4,8 \mathrm{~g} \mathrm{vaso}^{-1}$ no Planossolo foram de 10 a $28 \mathrm{~g}_{\text {vaso }}{ }^{-1}$. O Neossolo Regolítico ocupou uma posição intermediária com produções, na testemunha, de 9 a $13 \mathrm{~g}$ vaso $^{-1}$. Com o esterco, as produções no Planossolo subiram para 13 a 36 g vaso $^{-1}$, as do Neossolo Regolítico ficaram nesta mesma faixa ( $\left.17 \mathrm{a} 35 \mathrm{~g} \mathrm{vaso}^{-1}\right)$ e as do Neossolo Flúvico não alcançaram valores tão altos (13 a 22 g vaso $^{-1}$ ).

No tratamento sem esterco não houve diferenças significativas entre as forrageiras nos dois Neossolos; entretanto, no Planossolo a orelha de onça produziu mais que o buffel e a jureminha (Tabela 2). Com o esterco, o feijão de rolinha alcançou as maiores produções nos três solos, mostrando grande capacidade de resposta à adubação. A orelha de onça também produziu bem com o esterco, no Planossolo e no Neossolo Regolítico porém teve a produção mais baixa no Neossolo Flúvico. O buffel foi a forrageira de menor produção no tratamento adubado, embora não tenha diferido estatisticamente da jureminha, em nenhum dos três solos.

A melhor fertilidade do Planossolo Háplico (Tabela 1) deve ter favorecido a maior produção de biomassa das forrageiras (Tabela 2), na ausência do esterco. Os estudos de adubação orgânica com essas forrageiras são escassos, particularmente com as três leguminosas nativas, pouco estudadas fora e até mesmo dentro da região nordestina. Há mais informações sobre o capim buffel, um capim introduzido no Nordeste e com ampla disseminação em áreas secas tropicais do mundo. No semiárido nordestino o buffel foi pesquisado por Dantas Neto et al. (2000) e por Silva \& Menezes (2007), em que os primeiros avaliaram a influência da precipitação e da idade da planta ao primeiro corte sobre a produção de massa seca e composição química do capim. Silva $\&$ Menezes (2007) encontraram resposta do buffel a adubações com $15 \mathrm{Mg} \mathrm{ha}^{-1}$ de esterco e com 7,5 $\mathrm{Mg} \mathrm{ha}^{-1}$ de esterco incorporado em conjunto com igual dose de crotalária, como adubo verde.

\section{Concentração de nutrientes}

As concentrações de $\mathrm{N}$ nas quatro forrageiras não diferiram significativamente dentro de cada solo e de cada tratamento (Tabela 3). Na testemunha, os valores oscilaram entre 9 e 15 $\mathrm{mg} \mathrm{g}^{-1} \mathrm{e}$, no tratamento com esterco, entre 10 e $19 \mathrm{mg} \mathrm{g}^{-1}$. A média no Planossolo Háplico foi de $15,0 \mathrm{mg} \mathrm{g}^{-1}$; no Neossolo Flúvico, 13,2 $\mathrm{mg} \mathrm{g}^{-1}$ e no Neossolo Regolítico, 11,7 mg g-1 . São concentrações baixas, especialmente para as leguminosas que, em geral, têm valores mais altos (entre 20 e $40 \mathrm{mg} \mathrm{g}^{-1}$ ) que as não leguminosas (15 a $20 \mathrm{mg} \mathrm{g}^{-1}$ ), mesmo quando não são fixadoras do $\mathrm{N}$ atmosférico (Freitas, 2008). As baixas concentrações obtidas em todas as situações indicam que o $\mathrm{N}$ pode ter sido um fator limitante ao crescimento das plantas mesmo no tratamento com adubação orgânica; indicam, também, que as leguminosas não estavam fixando ou que a contribuição da fixação foi pequena.

As concentrações de $\mathrm{P}$ nas quatro espécies, tal como as de $\mathrm{N}$, não diferiram estatisticamente dentro de cada solo e dos tratamentos com e sem adubação (Tabela 3). A adubação resultou em acréscimo de duas a três vezes nas concentrações médias em relação às da testemunha: nos dois Neossolos passou de 0,7 a $1,8 \mathrm{mg} \mathrm{g}^{-1}$ enquanto no Planossolo passou de 0,9 a $2,2 \mathrm{mg} \mathrm{g}^{-1}$. As concentrações na testemunha podem ser consideradas baixas, indicando possível deficiência de $\mathrm{P}$, em acréscimo à de N. Com o esterco, as concentrações passaram a valores considerados adequados sinalizando para o fato de que a adubação supriu as necessidades de $\mathrm{P}$ às plantas. $\mathrm{Na}$ verdade, o esterco bovino tem sido reconhecido como uma boa fonte de P (Menezes \& Silva, 2008; Galvão et al., 2008).

As concentrações de $\mathrm{K}$ das espécies não foram semelhantes, diferente do que ocorreu com $\mathrm{N}$ e com P (Tabela 3); as de buffel (13 a $21 \mathrm{mg} \mathrm{g}^{-1}$ ) foram mais altas que as das três espécies de leguminosas (3 a $11 \mathrm{mg} \mathrm{g}^{-1}$ ), independente do solo e da

Tabela 2. Produção de massa seca da parte aérea de quatro forrageiras em função do tipo de solo e da aplicação do esterco

\begin{tabular}{|c|c|c|c|c|c|c|}
\hline \multirow{4}{*}{ Forrageiras } & \multicolumn{2}{|c|}{ Neossolo Flúvico } & \multirow{2}{*}{\multicolumn{2}{|c|}{$\begin{array}{c}\text { Neossolo Regolítico } \\
\text { Esterco }\left(\mathrm{Mg} \mathrm{ha}^{-1}\right)\end{array}$}} & \multicolumn{2}{|c|}{ Planossolo Háplico } \\
\hline & \multicolumn{4}{|c|}{ Esterco (Mg ha $\left.{ }^{-1}\right)$} & & \\
\hline & 0 & 20 & 0 & 20 & 0 & 20 \\
\hline & \multicolumn{6}{|c|}{$\left(\right.$ g vaso $\left.^{-1}\right)$} \\
\hline Orelha de onça & $4,75 a B^{1}$ & $13,25 \mathrm{~b} \mathrm{~A}$ & 13,25 a $B$ & $32,50 \mathrm{ab} A$ & 27,75 a B & 34,50 a $A$ \\
\hline Buffel & 3,25 a B & $15,75 a b A$ & 9,00 a B & $17,00 \mathrm{CA}$ & 13,25 bc $A$ & $13,00 \mathrm{~b} \mathrm{~A}$ \\
\hline J ureminha & 4,75 a $B$ & $19,50 a b A$ & 13,00 a B & 24,50 bc $A$ & 10,25 C B & $20,75 \mathrm{~b} \mathrm{~A}$ \\
\hline Feijão de rolinha & 2,00 a B & 22,25 a A & 9,75 a B & 35,50 a $A$ & $21,25 a b B$ & 36,00 a $A$ \\
\hline
\end{tabular}

${ }^{1}$ Médias seguidas da mesma letra minúscula na coluna e maiúscula na linha, dentro de cada solo, não diferem entre si pelo teste de Tukey a $5 \%$ de probabilidade 
Tabela 3. Teores de nitrogênio, fósforo e potássio na parte aérea de forrageiras em função do tipo de solo e da aplicação do esterco bovino

\begin{tabular}{|c|c|c|c|c|c|c|}
\hline \multirow{3}{*}{ Forrageiras } & \multicolumn{2}{|c|}{ Neossolo Flúvico } & \multicolumn{2}{|c|}{ Neossolo Regolítico } & \multicolumn{2}{|c|}{ Planossolo Háplico } \\
\hline & \multicolumn{6}{|c|}{ Esterco bovino ( $\mathrm{Mg} \mathrm{ha}^{-1}$ ) } \\
\hline & 0 & 20 & 0 & 20 & 0 & 20 \\
\hline & \multicolumn{6}{|c|}{$\mathrm{N}\left(\mathrm{mg} \mathrm{g}^{-1}\right)$} \\
\hline Orelha de onça & 12,03 a $A^{(1)}$ & 17,11 a $A$ & 11,48 a $\mathrm{A}$ & 14,35 a $\mathrm{A}$ & 14,99 а $A$ & 15,65 a $A$ \\
\hline Buffel & 9,15 a $A$ & 13,44 a $A$ & 12,14 a $A$ & 9,96 а $A$ & 13,44 a $\mathrm{A}$ & 13,10 a $A$ \\
\hline J ureminha & 14,21 a $A$ & 14,26 a $A$ & 7,66 a $A$ & 12,13 a $A$ & 11,24 a B & 19,00 a $A$ \\
\hline \multirow[t]{2}{*}{ Feijão-de-rolinha } & 9,90 a A & 15,21 a $A$ & 14,75 a $\mathrm{A}$ & 10,59 a A & 16,08 a $\mathrm{A}$ & 15,19 a A \\
\hline & \multicolumn{6}{|c|}{$P\left(\mathrm{mg} \mathrm{g}^{-1}\right)$} \\
\hline Orelha de onça & 0,66 a $B$ & 1,96 а $A$ & 0,52 a $B$ & 1,96 a $A$ & 0,57 a $B$ & 2,43 a $A$ \\
\hline Buffel & 0,72 a $B$ & 2,25 a $A$ & 0,67 a B & 1,88 a $A$ & 1,34 a $B$ & 2,30 a $A$ \\
\hline J ureminha & 0,83 a $B$ & 1,65 a $A$ & 0,95 a $B$ & 2,06 a $A$ & 1,15 a $A$ & 1,84 a $A$ \\
\hline \multirow[t]{2}{*}{ Feijão-de-rolinha } & 0,67 a $\mathrm{A}$ & 1,33 a $\mathrm{A}$ & 0,61 a $B$ & 1,55 a $\mathrm{A}$ & $0,67 a \mathrm{~B}$ & 2,37 a $\mathrm{A}$ \\
\hline & \multicolumn{6}{|c|}{$\mathrm{K}\left(\mathrm{mg} \mathrm{g}^{-1}\right)$} \\
\hline Orelha de onça & $4,65 \mathrm{~b} \mathrm{~A}$ & 7,27 b A & 5,22 b B & $9,85 \mathrm{~b} \mathrm{~A}$ & 6,45 b B & $11,27 a b$ A \\
\hline Buffel & 20,07 a $A$ & 18,60 a $A$ & 13,02 a $B$ & 25,55 a $A$ & 14,62 a $A$ & 16,17 a $A$ \\
\hline J ureminha & 7,27 b A & $8,25 \mathrm{~b} \mathrm{~A}$ & $6,95 \mathrm{~b} \mathrm{~A}$ & $9,85 \mathrm{~b} A$ & $6,77 \mathrm{~b} \mathrm{~A}$ & $9,80 \mathrm{~b} \mathrm{~A}$ \\
\hline Feijão-de-rolinha & $3,35 \mathrm{~b} \mathrm{~A}$ & $6,32 \mathrm{~b} \mathrm{~A}$ & $4,62 \mathrm{~b} \mathrm{~B}$ & $10,10 \mathrm{~b} \mathrm{~A}$ & $6,00 \mathrm{~b} \mathrm{~A}$ & $8,37 \mathrm{~b} \mathrm{~A}$ \\
\hline
\end{tabular}

1) Médias seguidas da mesma letra minúscula na coluna para cada elemento e maiúscula na linha, para cada solo, não diferem pelo teste de Tukey a $\%$ de probabilidade

adubação. Por outro lado, só em poucos casos houve aumentos significativos das concentrações com a adubação e as diferenças entre solos foram pequenas e não significativas. Os teores constatados na parte aérea do capim buffel podem ser considerados adequados apesar dos das leguminosas terem sido relativamente baixos. Como os conteúdos no buffel foram, em geral, maiores que nas leguminosas, sobretudo na testemunha (Tabela 4), não parece que os baixos teores nas leguminosas possam ser atribuídos à limitação no suprimento, parecendo mais que o capim tem capacidade de absorção bem mais alta que as outras três espécies.

\section{Conteúdo de nutrientes}

A comparação dos conteúdos de $\mathrm{N}$ nas plantas (Tabela 4) nos tratamentos com e sem adubação, reforça a idéia de limitação do crescimento por falta de suprimento de N. Os conteúdos aumentaram muito com a adubação, em todas as espécies, mas foram proporcionais aos aumentos das biomassas mostrando que o $\mathrm{N}$ absorvido foi diluído na biomassa formada sem aumentos expressivos nas concentrações (Tabela 3), caracterizando o efeito de diluição (Jarrel \& Beverly, 1981). Nos dois Neossolos os aumentos médios nos conteúdos de $\mathrm{N}$ foram de pouco mais de $200 \mathrm{mg}$ vaso $^{-1}$ (203 e $218 \mathrm{mg} \mathrm{vaso}^{-1}$, no N. Regolítico e $218 \mathrm{mg}$ vaso $^{-1}$ no N. Flúvico), enquanto no Planossolo foram de 163 mg vaso ${ }^{-1}$, sugerindo que o $\mathrm{N}$ do esterco disponibilizado para absorção pelas plantas estava em torno de $200 \mathrm{mg} \mathrm{vaso}^{-1}$ e no Planossolo toda esta quantidade não foi absorvida visto que, no Planossolo, teria havido uma pequena sobra de $\mathrm{N}$ não absorvido possivelmente por deficiência de outro nutriente ou pela própria capacidade de acumulação de massa das plantas, já que foi neste solo as plantas mais acumularam $\mathrm{N}$, em termos absolutos, e tiveram as maiores concentrações na massa seca (Tabela 3).

Tabela 4. Acúmulo de nitrogênio, fósforo e potássio na parte aérea de forrageiras em função do tipo de solo e da aplicação do esterco bovino

\begin{tabular}{|c|c|c|c|c|c|c|}
\hline \multirow{3}{*}{ Forrageiras } & \multicolumn{2}{|c|}{ Neossolo Flúvico } & \multicolumn{2}{|c|}{ Neossolo Regolítico } & \multicolumn{2}{|c|}{ Planossolo Háplico } \\
\hline & & & Estercc & $\mathrm{Mg} \mathrm{ha}^{-1}$ ) & & \\
\hline & 0 & 20 & 0 & 20 & 0 & 20 \\
\hline $\begin{array}{l}\text { Orelha de onça } \\
\text { Buffel } \\
\text { J ureminha } \\
\text { Feijão-de-rolinha }\end{array}$ & $\begin{array}{l}57,0 \text { a } B^{(1)} \\
33,0 \text { a B } \\
64,0 \text { a B } \\
19,0 \text { a B }\end{array}$ & $\begin{array}{l}226,0 \text { a A } \\
199,0 \text { a A } \\
275,0 \text { a A } \\
345,0 \text { a A }\end{array}$ & $\begin{array}{r}159,0 \text { a B } \\
113,0 \text { a } A \\
97,0 \text { a } B \\
141,0 \text { a B } \\
\end{array}$ & $\begin{array}{l}-1) \\
474,0 \text { a A } \\
166,0 \text { b A } \\
290,0 \text { ab A } \\
390,0 \text { a A }\end{array}$ & $\begin{array}{l}419,0 \text { a A } \\
150,0 \text { b A } \\
116,0 \text { b B } \\
329,0 \text { ab B }\end{array}$ & $\begin{array}{l}547,0 \text { a A } \\
178,0 \text { b A } \\
392,0 \text { ab A } \\
547,0 \text { a A }\end{array}$ \\
\hline $\begin{array}{l}\text { Orelha de onça } \\
\text { Buffel } \\
\text { J ureminha } \\
\text { Feijão-de-rolinha }\end{array}$ & $\begin{array}{l}3,1 \text { a B } \\
2,4 \text { a B } \\
3,4 \text { a B } \\
1,3 \text { a B }\end{array}$ & $\begin{array}{l}26,1 \text { a } A \\
35,8 \text { a A } \\
33,1 \text { a A } \\
29,7 \text { a A } \\
\end{array}$ & $\begin{array}{r}\quad P \\
5,8 \text { a B } \\
6,0 \text { a B } \\
12,6 \text { a B } \\
5,9 \text { a B } \\
\end{array}$ & $\begin{array}{l}-1 \text { ) } \\
63,6 \text { a A } \\
32,3 \text { b A } \\
47,8 \text { ab A } \\
55,2 \text { a A }\end{array}$ & $\begin{array}{l}15,4 \text { a } B \\
18,0 \text { a } A \\
12,0 \text { a } B \\
12,9 \text { a } B\end{array}$ & $\begin{array}{l}83,6 \text { a A } \\
29,6 \text { b A } \\
38,5 \text { b A } \\
79,4 \text { a A }\end{array}$ \\
\hline $\begin{array}{l}\text { Orelha de onça } \\
\text { Buffel } \\
\text { J ureminha } \\
\text { Feijão-de-rolinha }\end{array}$ & $\begin{array}{r}22,0 \text { a } A \\
67,0 \text { a B } \\
32,0 \text { a B } \\
6,0 \text { a B }\end{array}$ & $\begin{array}{r}94,0 \text { b A } \\
290,0 \text { a A } \\
173,0 \text { b A } \\
140,0 \text { b A }\end{array}$ & $\begin{array}{r}73,0 \text { a B } \\
117,0 \text { a B } \\
89,0 \text { a B } \\
44,0 \text { a B }\end{array}$ & $\begin{array}{l}-1) \\
308,0 \text { ab A } \\
444,0 \text { a A } \\
224,0 \text { b A } \\
360,0 \text { ab A }\end{array}$ & $\begin{array}{r}178,0 \text { a } B \\
199,0 \text { a } A \\
70,0 \text { a B } \\
130,0 \text { a B }\end{array}$ & $\begin{array}{l}394,0 \text { a A } \\
204,0 \text { b A } \\
205,0 \text { b A } \\
307,0 \text { ab A }\end{array}$ \\
\hline
\end{tabular}


Com base no acréscimo de $\mathrm{N}$ nas plantas no tratamento com esterco em comparação com o não adubado (em torno de $200 \mathrm{mg} \mathrm{vaso}^{-1}$ ) como a contribuição do esterco e se sabendo a quantidade de $\mathrm{N}$ aplicada, pode-se estimar a eficiência aparente de utilização do $\mathrm{N}$ fornecido pelo esterco. Como a quantidade de $\mathrm{N}$ do esterco não foi determinada pode-se assumir a faixa de valores encontrados nas análises de esterco, semelhantes na região (Sampaio et al., 2007; Garrido et al., 2008). Esta faixa vai de 10 a $11 \mathrm{mg} \mathrm{N} \mathrm{g}^{-1}$ de esterco que, multiplicados pelos $55 \mathrm{~g}$ de esterco por vaso, dariam 550 a $605 \mathrm{mg} \mathrm{N}$ vaso $^{-1}$, correspondendo a eficiências de utilização aparentes de cerca de 33\%. São eficiências superiores às encontradas por Sampaio et al. (2007).

Como as diferenças nas concentrações de $\mathrm{P}$ foram pequenas dentro de cada tratamento de adubação, as diferenças nos conteúdos de $\mathrm{P}$ (Tabela 4) refletem as diferenças em biomassa; assim, o conteúdo médio no tratamento testemunha constatado no Planossolo ( $15 \mathrm{mg}$ vaso $^{-1}$ ), foi maior que nos dois Neossolos (8 e $3 \mathrm{mg}$ vaso $^{-1}$, no N. Regolítico e no N. Flúvico, respectivamente); com a adubação, somou-se o aumento em biomassa com o aumento em concentração de $\mathrm{P}$ resultando em grandes acréscimos nos conteúdos das plantas, em todos os solos. Proporcionalmente, esses aumentos foram maiores no Neossolo Flúvico (aumento médio de 12 vezes, para $31 \mathrm{mg}$ vaso $^{-1}$ ), em razão dos conteúdos muito baixos no tratamento sem adubação porém os conteúdos absolutos com o esterco foram maiores no Planossolo (58 $\mathrm{mg} \mathrm{vaso}^{-1}$, aumento de 4 vezes) e no Neossolo Regolítico (50 mg vaso ${ }^{-1}$, aumento de 6 vezes). Também, os acréscimos absolutos com a adubação foram maiores nesses dois solos (43 e $42 \mathrm{mg}$ vaso $^{-1}$, contra $29 \mathrm{mg}$ vaso $^{-1}$, no Neossolo Flúvico) e indicam o potencial de fornecimento de $\mathrm{P}$ do esterco.

A eficiência de utilização aparente do $\mathrm{P}$ do esterco pode ser calculada admitindo-se as mesmas hipóteses feitas para o cálculo com relação ao $\mathrm{N}$ e se tomando o valor médio de concentração de P no esterco como 6,5 mg g-1 (Garrido et al., 2008). A aplicação corresponderia a $357 \mathrm{mg}$ vaso $^{-1} \mathrm{e}$ a eficiência aparente do $\mathrm{P}$, no caso de acréscimo de $43 \mathrm{mg}$ vaso $^{-1}$, seria de cerca de $12 \%$; trata-se de um valor bem próximo dos 9 a $11 \%$ constatados por Sampaio et al. (2007) e do valor máximo (2 a $11 \%$ ) obtido por Blaise et al. (2005) mas inferior aos referidos por Reddy et al. (1999) que chegaram a 167\%, com aplicações cinco anos seguidos, em conjunto com a adubação mineral.

As diferenças nos conteúdos das plantas crescidas nos três solos, sem adubação, refletem a ordem de disponibilidade de K: maior no Plansossolo (144 $\mathrm{mg} \mathrm{vaso}^{-1}$ ), intermediária no Neossolo Regolítico (81 mg vaso ${ }^{-1}$ ) e menor no Neossolo Flúvico (32 mg vaso $\left.{ }^{-1}\right)$. Com a adubação, os conteúdos aumentaram de 2 a 5 vezes, seguindo os aumentos em biomassa e com pequena contribuição dos aumentos nas concentrações. Os aumentos absolutos médios nos três solos variaram de 133 a $253 \mathrm{mg} \mathrm{vaso}^{-1}$ e corresponderiam a eficiências aparentes de utilização de 17 a $32 \%$ considerando-se que o esterco tivesse $14,4 \mathrm{mg} \mathrm{g}^{-1}$ (Garrido et al., 2008). As eficiências encontradas por Sampaio et al. (2007) foram da mesma ordem (26 a 34\%), assim como as de Blaise et al. (2005) para aplicações isoladas de esterco (14 a 41\%), mas esses últimos autores também relataram valores negativos, bem acima de $100 \%$. Como o Ké um elemento pouco retido nos tecidos vegetais, mesmo os já digeridos, a forma de tratamento dos estercos tem grande influência na concentração final e na disponibilidade. Reconhecendo a variabilidade, o esterco é, em geral, considerado uma fonte pobre de $\mathrm{K}$, ainda que a disponibilidade seja tão ou mais alta que as de P e de N.

Para os três nutrientes analisados o Planossolo Háplico teve maior capacidade de fornecimento às plantas que os dois Neossolos e, entre esses, o Regolítico maior que o Flúvico; entretanto, o Planossolo apresentou os menores teores de $\mathrm{P}$ e de K extraíveis com Mehlich-1 e se destacou apenas quanto aos maiores teores de C orgânico e de Ca e Mg (Tabela 1). Em geral, os Planossolos não estão entre os solos preferidos para cultivo no semiárido nordestino, por conta de suas características físicas mas também pelos baixos teores de $\mathrm{P}$ total na camada superficial, ainda que boa parte deste P seja extraível (Silveira et al., 2006). Por outro lado, os Neossolos Flúvicos do semiárido nordestino estão. em geral, entre as ordens de maiores teores de $\mathrm{P}$ total e de $\mathrm{P}$ extraível e entre as preferidas para cultivo (Silveira et al., 2006). O Neossolo Flúvico de Esperança, $\mathrm{PB}$, teve, entre os três solos usados, os maiores teores de $\mathrm{P}$ extraível e de $\mathrm{C}$ orgânico porém esta superioridade não se traduziu em maiores absorções de $\mathrm{P}$ e de $\mathrm{N}$ nas plantas nele cultivadas nem houve correspondência entre os teores de $\mathrm{K}$ nos solos e os conteúdos nas plantas, fato exemplificado pelos teores muito mais altos no Neossolo Regolítico que no Planossolo, contrastando com os conteúdos verificados na parte aérea das leguminosas serem mais altos quando cultivados no Planossolo. Esses resultados são indicadores de que a nutrição das plantas tem padrão complexo e que as análises de solo precisam ser interpretadas com cautela.

\section{CONCLusões}

1. A adubação com esterco promoveu grandes incrementos na produção de biomassa e nas acumulações de N, P e K, em todas as plantas e solos. Apesar do menor valor, o esterco parece ter suprido $\mathrm{P}$ às plantas em quantidades suficientes mas não $\mathrm{N}$ e $\mathrm{K}$, confirmando que é uma boa fonte do primeiro elemento.

2. O feijão de rolinha e a orelha de onça parecem ter maior capacidade de acumulação de biomassa que a jureminha e o buffel, sobremaneira em resposta à adubação. O buffel atinge maiores teores e conteúdos de $\mathrm{K}$ na matéria seca que as leguminosas, indicando maior capacidade de absorção de $\mathrm{K}$ do solo.

3. O Planossolo Háplico forneceu mais N, P e K às plantas que os Neossolos, apesar de ter os menores teores de $\mathrm{P}$ e $\mathrm{K}$ extraíveis enquanto o Neosssolo Flúvico, com o maior teor de P, forneceu a menor quantidade; portanto, não houve correspondência entre a análise dos solos e suas capacidades de suprimento de nutrientes.

\section{LITERATURA CITADA}

Ambrosano, E. J.; Trivelin, P. C.; Cantarella, H.; Ambrosano, M. B.; Schammass, E. A.; Muraoka, T.; Guirado, N.; Rossi, F. Nitrogen supply to corn from summ hemp and velvet bean Green manures. Scientia Agrícola, v.66, p.386-394. 2009. 
Blaise, D.; Singh, J. V.; Bonde, A. N.; Tekale, K. U.; Mayee, C. D. Effects of farmyard manure and fertilizers and yield, fibre quality and nutrient balance of rainfed cotton (Gossipium hirsutum. Bioresource Technology, v.96, p.345-349, 2005.

Dantas Neto, J.; Silva, F. de A. S. e; Furtado, D. A.; Matos, J. de A. Influência da precipitação e idade da planta na produção e composição química do capim-buffel. Pesquisa Agropecuária Brasileira, v.35, p.1867-1874, 2000.

EMBRAPA - Embrapa Brasileira de Pesquisa Agropecuária. Serviço Nacional de Levantamento e Conservação de Solos. Manual de métodos de análise de solos. 2 ed. Rio de Janeiro: EMBRAPA, 1997. 212p.

Ferreira, D. Sisvar software: Versão 4.6. Lavras: DEX/UFLA, 2003. Software.

Fraga, V. de S.; Salcedo, I. H. Declines of organic nutrient pools in Tropical Semi-Arid soils under subsistence farming. Soil Science Society America Journal, v.68, p.215-224, 2004.

Franco, A. A.; Neves, M. C. P. Fatores limitantes à fixação biológica de nitrogênio. In: Cardoso, E. J. B. N.; Tsai, S. M.; Neves, M. C. P. (Coord.). Microbiologia do solo. Campinas, 1992.p.219-230.

Freitas, A. D. S. Abundância natural do ${ }^{15} \mathrm{~N}$ e fixação biológica do $\mathrm{N}_{2}$ em espécies arbóreas da caatinga. Recife: UFPE, 2008. 65p. Tese Doutorado

Galvão, S. R. S.; Salcedo, I. H.; Oliveira, F. F. Acumulação de nutrientes em solos arenosos adubados com esterco bovino. Pesquisa Agropecuária Brasileira. v.43, p.99-105, 2008.

Garrido, M. S.; Sampaio, E. V. S. B.; Menezes, R. S. C. Potencial de adubação orgânica com esterco no Nordeste do Brasil. In: Menezes, R. S. C.; Salcedo, I. H.; Sampaio, E. V. S. B. (Ed.). Fertilidade do solo e produção de biomassa no semiárido. Recife: UFPE. 2008. p.123-140.

Jarrel, W. M.; Beverly, R. B. The dilution effect in plant nutrition studies. Advances in Agronomy, v.34, 1981, p.197-224.

Krolow, R. H.; Mistura, C.; Coelho, R. W.; Siewerdt, L.; Zonta, E. P. Efeito do fósforo e do potássio sobre o desenvolvimento e a nodulação de três leguminosas anuais de estação fria. Revista Brasileira de Zootecnia, v.33, p.2224-2230, 2004.

Malavolta, E.; Vitti, G. C.; Oliveira, S. A. de. Avaliação do estado nutricional das plantas: Princípios e aplicações. 2.ed. Piracicaba: Potafos, 1997.319p.

Martins, L. M. V.; Xavier, G. R.; Rangel, F. W.; Ribeiro, J. R. A.; Neves, M. C. P.; Morgado, L. B.; Rumjanek, N. G. Contribution of biological nitrogen fixation to cowpea: a strategy for improving grain yield in the semi-arid region of Brazil. Biology Fertility Soils, v.38, p.333-339, 2003.

Menezes, R. S. C.; Sampaio, E. V. de S. B. Agricultura sustentável no semi-árido nordestino. In: Oliveira, T. S.; Romero, R. E.; Assis Jr., R. N.; Silva, J. R. C. S., (eds). Agricultura, sustentabilidadee o semi-árido. Fortaleza: SBCS/UFC, 2000. p.20-46.

Menezes, R. S. C.; Sampaio, E. V. de S. B. Simulação dos fluxos e balanços de fósforo em uma unidade de produção agrícola familiar no semi-árido paraibano. In: Silveira, L. M.; Petersen, P.; Sabourin, E. (ed.). Agricultura familiar e agroecologia no semiárido: Avanços a partir do agreste da Paraíba. Rio de Janeiro: AS-PTA, 2002. p.249-260.
Menezes, R. S. C.; Silva, T. O. Mudanças na fertilidade de um Neossolo Regolítico após seis anos de adubação orgânica. Revista Brasileira de Engenharia Agrícola e Ambiental, v.12, p.251-257, 2008.

Moreira, F. M. S.; Siqueira, J. O. Microbiologia e bioquímica do solo. 2.ed. Lavras: UFLA, 2006. 729p.

Patreze, C. M.; Cordeiro, L. Nodulation, arbuscular mycorrhizal colonization and growth of some legumes natives from Brazil. Acta Botanica. Brasílica, v.19, p.527-537, 2005.

Reddy, D. D.; Rao, A. S.; Reddy, K. S.; Takkar, P. N. Yield sustainability and phosphorus utilization in soybean-wheat system on Vertisols in response to integrated use of manure and fertilizer phosphorus. Field Crops Research, v.62, p.181190, 1999.

Sampaio, E. V. de S. B.; Freitas, A. D. S. Produção de biomassa na vegetação nativa do solo semi-árido nordestino. In: Menezes, R. S. C.; Sampaio, E. V. S. B; Salcedo, I. H. (Org.). Fertilidade do solo e produção de biomassa no semi-árido. Recife: UFPE, 2008. p.11-25.

Sampaio, E. V. de S. B.; Oliveira, N. M. B.; Nascimento, P. R. F. Eficiência da adubação orgânica com esterco bovino e com Egeria densa. Revista Brasileira de Ciência do Solo v.31, p.995-1002, 2007.

Silva, T. O. da; Menezes, R. S. C. Adubação orgânica da batata com esterco e, ou, Crotalaria juncea. II. Disponibilidade de N, P e K no solo ao longo do ciclo de cultivo. Revista Brasileira de Ciência do Solo, v.31, p.51-61, 2007.

Silva, T. O. da; Menezes, R. S. C.; Tiessen, H.; Sampaio, E. V. S. B.; Salcedo, I. H.; Silveira, L. M. Adubação orgânica da batata com esterco e, ou, Crotalaria juncea. I. Produtividade vegetal e estoque de nutrientes no solo em longo prazo. Revista Brasileira de Ciência do Solo, v.31, p.39-49, 2007.

Silveira, M. M. L.; Araújo, M. S. B.; Sampaio, E. V. de S. B. Distribuição de fósforo em diferentes ordens de solo do semi-árido da Paraíba e de Pernambuco. Revista Brasileira de Ciência do Solo, v.30, p.281-291, 2006.

Snyder, J. D.; Trofymow, J. A. A rapid accurate wet oxidation diffusion procedure for determining organic and inorganic carbon in plant and soil samples. Communications in Soil Science Plant Analysis, v.15, p.587-597, 1984.

Souza, L. A. G.; Bezerro Neto, E.; Santos, C. E. R. S.; Stamford, N. P. Desenvolvimento e nodulação natural de leguminosas arbóreas em solos de Pernambuco. Pesquisa Agropecuária Brasileira, v.42, p.207-217, 2007.

Teixeira, F. C. P.; Reinert, F.; Rumjanek, N. G.; Boddey, R. M. Quantification of the contribuition of biological nitrogen fixation to Cratylia mollis using the ${ }^{15} \mathrm{~N}$ natural abundance technique in the semi-arid caatinga region of Brazil. Soil Biology \& Biochemistry, v.38, p.1989-1993, 2006.

Xavier, T. F.; Araújo, A. S. F.; Santos, V. B.; Campos, F. L. Ontogenia da nodulação em duas cultivares de feijão-caupi. Ciência Rural, v.37, p.561-564, 2007. 